\title{
Early Adopters of the Internet and Social Media in Cuba
}

\author{
Michaelanne Dye, Annie Antón, Amy S. Bruckman \\ School of Interactive Computing \\ Georgia Institute of Technology \\ $855^{\text {th }}$ St. NW, Atlanta, GA 30332 USA \\ mdye@gatech.edu, aianton; asb@cc.gatech.edu
}

\begin{abstract}
Although the Cuban government has tightly controlled information access for more than half a century, a small number of Cubans have access at work. In this paper, we examine Internet and social media use by early adopters in Cuba in early 2015, as we enter a time of potential change. Specifically, we explore Cubans' access limitations and the activities they do online, as well as what Internet access means to them. We conducted interviews with 12 Cuban Internet users and observed their social media use. Our findings suggest that access limitations and slow network speeds greatly restrict Cubans' Internet use. To counter these limitations, Cubans are collaborative, often conducting online research and posting photos for friends with less access. Based on these findings, we propose future work to help meet Cuban citizens' information needs.
\end{abstract}

\section{Author Keywords}

Social media; social computing; Facebook; Latin America; Cuba; qualitative methods; interviews

\section{ACM Classification Keywords}

H.5.3. [Group and Organization Interfaces]: Collaborative Computing

\section{INTRODUCTION}

"Now I have contact with the rest of the world. I've stopped living in the bubble."

-- Cuban citizen with Internet access (P1)

In a country where information was tightly controlled for more than 50 years, people are eager to access content long out of reach. In December 2014, the United States and Cuba announced that they intend to normalize relations $[5,44]$. One potential consequence may be greatly increased access to the Internet for Cuban citizens. Our study began in fall 2014, shortly before this announcement. Considering the potential for drastic change, as well as the unique space that

Permission to make digital or hard copies of all or part of this work for personal or classroom use is granted without fee provided that copies are not made or distributed for profit or commercial advantage and that copies bear this notice and the full citation on the first page. Copyrights for components of this work owned by others than the author(s) must be honored. Abstracting with credit is permitted. To copy otherwise, or republish, to post on servers or to redistribute to lists, requires prior specific permission and/or a fee. Request permissions from Permissions@acm.org.

CSCW '16, February 27-March 02, 2016, San Francisco, CA, USA Copyright is held by the owner/author(s). Publication rights licensed to ACM.

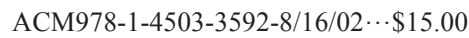

DOI: httb://dx.doi.org/10.1145/2818048.2819947
Cuba represents, this research attempts to capture the situation in Cuba at this moment in time. Through interviews with 12 Cuban Internet users and observation of their social media use, we explore the impact of Internet access on the daily life and worldview of Cuban early adopters of Internet technology. We seek to answer questions such as: which Cubans currently have Internet access, how do they use it now, and how do they hope to use it in the future? What hopes do Cubans have for a more networked future?

Understanding the situation for early Internet adopters in Cuba is, first, of interest for researchers, corporations, and others hoping to engage more directly with Cuba in the future. Second, insights developed from understanding this unusual situation may provide insights into the role of the Internet and social media in other countries. We draw from other work on design implications for the urban poor in developing countries that, "calls for developing ICT interventions grounded in users' existing practices rather than introducing new and unfamiliar ones" [54].

Miller and Slater argue that there is significant intellectual value in "producing material that will allow us to understand the very different universes of social and technical possibility that have developed around the Internet in, say, Trinidad versus Indonesia, or Britain versus India" [32]. Within those universes of social and technical possibility, Cuba is unique in combining extremely low access to both Internet and telephone with a highly literate population [9]. The broader social context includes crumbling infrastructure and chronic food shortages $[27,47]$. Thus, the challenges for Cuban Internet users are quite different from those of Iraq [29] or Mexico [33] during wartime, rural India [1], Africa [2], native American reservations in the US [38], or other developing locations.

Miller and Slater continue that, "Each of these places is constantly being redefined through engagements with forces such as the Internet" [32]. Is Cuba at this particular historical moment in any meaningful sense "being redefined" by the Internet? We begin to develop insights into that question using qualitative research methods. More broadly, by examining this particular situation in the world of social and technical possibilities, what insights can we draw for the use of information and communication technologies (ICTs) for low-access spaces in other parts of 
the world? This paper serves as an exploratory study of an understudied space while also laying a baseline for future work in this country.

\section{BACKGROUND}

Cuba has been called the second most isolated country in the world, partially due to its tightly controlled Internet [49]. Reasons for this Internet stagnation include lack of resources, the US embargo against Cuba, and the Cuban government's fear of implications of the freedom of information $[17,35]$. However, this was not always the case. Cuba was once the most connected country in the Caribbean, accounting for nearly $32 \%$ of all email traffic and international news [35]. In the early 90s, Cuba seemed positioned to grow in the computing sector with some predicting faster change in Cuba than in the former Soviet Union because of the small population and the potential for aid from the large expatriate community located nearby [31]. In 1996, with assistance from the NSF, Cuba connected to the Internet and government officials seemed positive about its potential use in Cuba [35]. However, five years later, Cuba was at the lowest point in six dimensions of Internet access [52]. Cuba's Internet has stagnated with little improvement since the late 90 s [35].

Changes during the last five years place Cuba in the midst of a technological upheaval, pitting government control against the desire for economic success [16]. In 2013, Cuba connected a high speed ALBA-1 fiber optic cable to Venezuela, enabling increased data transmission speeds [7]. Cuba was removed from the US state sponsors of terror list in May 2015, and formal diplomatic relations between the US and Cuba were established in July 2015 [10]. This will presumably yield significant growth in Internet access for Cuban citizens [5]. However, consistent blocks exist to Internet access, including policy restrictions, surveillance, and lack of resources. Even with more Internet penetration across the island, little has changed for most Cubans seeking information beyond state-controlled sources $[7,35]$.

The Cuban government continues to repress individuals and groups who criticize the government or call for basic human rights [17]. The government has been known to persecute dissident bloggers. For example, blogger Yoani Sanchez, whose posts frequently speak out against the government, has been imprisoned on several occasions [7]. Despite impediments to open communication online, our findings show that many Cubans are eager to communicate with one another, as well as the rest of the world.

Researchers on information and communication technologies for development (ICT4D) have shown that literacy poses a central challenge. Systems designed for rural India or Africa often leverage audio [1], audio and still pictures [30], video [41], or even bar codes [34] to ease technology use by low-literate individuals. In Cuba, the situation is quite different - the literacy rate is reported to be $99.8 \%$ [9]. We have been unable to confirm that statistic from multiple sources; however, regardless of the exact figure, it appears the literacy rate in Cuba is high. This suggests that the situation in Cuba may have commonalities with its Caribbean neighbor Trinidad, which also has a high basic literacy rate [32]. This raises the intriguing question of whether Cuba will follow Trinidad's pattern of extremely rapid adoption of the Internet going forwards, if access restrictions are lifted.

\section{RELATED WORK}

\section{Research on the Internet in Cuba}

How many Cubans currently have Internet access, how do they use it now, and how do they hope to use it in the future? Little empirical research has been published recently regarding Internet use in Cuba, and, to our knowledge, this work has been conducted in fields outside of CSCW. Pérez found that of 25 Cuban professionals, all reported minimal access to Information Technology (IT) yet expressed increased access as critical for development [18]. More recent work examines the Cuban blogosphere. To date, little research examines social network sites (SNS), such as Facebook and Twitter. Hoffman [25] argues that the need for public debate in Cuba is not mediated by the government, and the current blogger community in Cuba arose as a result of that need. According to Hoffman, through the blogosphere and e-mail, a virtual public sphere has formed; however, this has not deeply penetrated the physical world in Cuba. Other researchers suggest that online communication technologies have allowed for a more pluralized public space, bringing together microsites that were once segmented and isolated [19]. However, these online spaces are still limited to a select few, namely young intellectuals who are able to gain Internet access. Others have examined the blogosphere as an emergent public sphere in Cuba in which bloggers have forced their way into the public arena, challenging the ingrained narratives perpetuated by the Cuban regime. Therefore, the current blogosphere may present a model for democratic sociability in Cuba [13].

However, regardless of the popular discourse surrounding the 'liberating' nature of social media, the idea of the Internet potentially provoking a 'Cuban Spring' may be flawed due to the uniqueness of the Cuban situation [56]. When examining the Internet and state control in China and Cuba, authors contradict the notion that the Internet poses a threat to all authoritarian rule by demonstrating how both the Cuban and Chinese governments have been able to control and profit from the Internet $[25,26]$. Others advocate for further research in this area because of the complicated history of outside development actors attempting to use IT to promote democracy [15]. However, some argue that assistance from the international community will be key in advancing the state of technology in Cuba [18]. These papers provide an important contribution for examining social media use by Cuban 
activists, the state of the Internet in Cuba, and the importance of IT development on the island. We aim to extend prior work by incorporating the voice of Cubans who do not identify as activists into the narrative of Internet use in Cuba. By analogy, if we were to study just political discourse on the Internet in the United States, we would be looking at only a tiny fraction of online activity - much of the picture would be missing. Our work examines everyday Internet and social media use by early adopters in Cuba.

\section{Repressive Regimes and Conditions of Political Unrest}

Researchers have examined social media use in countries with repressive regimes as well as places with extreme political unrest $[4,33,40,53]$. Similar to recent work on Cuba, these studies primarily focus on political protest and activism. This work provides insights for work in countries with tightly controlled Internet access and where speaking out against the government may result in negative consequences. When examining the interplay between SNS and political change in Egypt, one study identified Facebook as an ideal tool for Egyptians to communicate and support mobilization, ultimately serving as a mechanism to circumvent the inherent lack of freedom of speech or the inability to gather in groups in the offline world [4]. Similarly, research on social media use in the Mexican Drug War notes the role of SNS for information curation among volatile populations [33]. Another study on online contribution practices in an undisclosed country identified strategies used by individuals to navigate Internet blocking such as self-censorship and reliance on social ties to relay blocked content [40].

Mark et al. [29] studied the use of social media by ordinary citizens during war time in Iraq. They document ways in which citizens use social media creatively to foster resilience in time of crisis, particularly:

- reconfiguring social networks (meeting new people online, because existing modes of socializing are not possible if travel is dangerous)

- self-organization (organizing shared resources, and collaboratively planning travel in dangerous areas)

- redundancy (sharing electrical power and Internet access)

- proactive practices (making educational materials available online to make sure they are accessible regardless of travel conditions)

- repairing trust in information (sharing information that has been verified and cross-checked by trustworthy people)

The needs of Cuban citizens are obviously quite different from the citizens struggling during wartime studied by Mark. However, a crumbling infrastructure and chronic shortages of food put significant stress on Cuban citizens $[27,47]$. Similar to Mark's subjects, our participants are struggling to adapt to disruption that has persisted over time. As we will see, Internet access for Cubans is currently so limited that many of the practices documented by Mark et al. are not yet apparent and arguably not yet possible.

\section{Low-Access Spaces}

Work in regions around the world show how persistent and creative individuals can be in obtaining Internet access. A study on political activists in a Palestinian village observed that, although the village lacked Internet access, individuals used Internet connections at workplaces and a $3 \mathrm{G}$ network through an Israeli mobile phone provider to bypass access issues [53]. Villagers were thereby able to take part in political activism via social media. In our study, workplaces are central to the state of the Internet in Cuba.

Once people obtain Internet access for the first time, what do they use it for? Early Internet use in US Native American reservations was funded for work and education; however, individuals were primarily using the Internet for entertainment purposes, similar to how typical individuals around the world use it [38]. Other studies observe that within one month of acquiring Internet access on mobile phones, Indian youth in slum communities access SNS such as Facebook [36,37]. A similar study in Kenya reveals growing online participation, primarily on Facebook, is limited by high costs, technology access, and unreliable electricity [55]. Our findings resonate with these studies regarding the central role of entertainment and socializing, and the importance of Facebook in particular.

Wyche et al. stress the importance of research to add value to participants' lives, a guiding principle that also motivates our work [55]. These studies help to frame our work within the larger context of Internet use in low-access spaces.

\section{METHODS}

Drawing methods from other similar studies [11,23,42], we performed 12 semi-structured interviews with citizens living in Cuba who do not identify as dissident bloggers. This was important because we sought to learn more about the average Cuban citizen's Internet use. We interviewed four females and eight males, ranging in age from 22-60 (see Table 1). Our participants by some measure may be considered elite; however, they live under similar economic conditions to those who do not have Internet access. We recruited participants until we felt that our data was saturated [22]. We used purposeful, snowball sampling to recruit initial participants through personal contacts. We then asked these contacts to refer us to additional contacts. The first author visited Cuba in March 2014, and was able to build a set of initial contacts who agreed to assist us in recruiting more individuals for this study. Our snowball sample began from multiple independent seeds. This method of sampling was the only one at our disposalmaking contact with participants was challenging. It is important to note that our sample is not representative (see section Limitations). Due to legal restrictions, we did not 
monetarily compensate participants. Interviews were conducted in 2015 from January $15^{\text {th }}$ through April $7^{\text {th }}$.

The new policy agreement between the US and Cuba calls for new efforts to increase Cubans' access to Internet services, as well as releasing several Cuban dissidents from Cuba's jails [44]. The policy change may make it less risky for Cubans to discuss sensitive topics more freely. All of our participants use email and SNS to communicate with individuals outside of Cuba on a regular basis. Each participant was aware that their online activity was (most likely) being monitored by the government and their employer. Our consent form cautioned participants to avoid topics they deemed controversial. Our protocol specifies that if a subject broached a topic that may be deemed controversial, we would interrupt them and remind them to be careful. However, this never happened during our interviews. We have anonymized all data that appears in this paper to further protect participants' privacy.

Interviews lasted between 30-90 minutes. Due to the difficulties surrounding access to communications, we allowed each participant to choose the interview method (Skype, phone, Facebook chat, or email) most convenient for them. Seven interviews were conducted via Facebook chat, three via email, one via Skype, and one via phone. Three interviews were conducted with participants who were traveling outside of Cuba for work purposes. Most Cubans have limited access to Internet and international phone calls to and from Cuba are expensive. Participating in interviews was much less burdensome for Cubans visiting other countries.

During the interviews, participants were asked questions about: Internet access, Internet use, social media sites, selfcensorship, Internet impact on their lives and culture, differences between Internet users and non-users, and the normalization of relations between Cuba and the United States. These interviews were semi-structured so that the interviewees were able to guide the flow of the conversation [23]. In email interviews, follow-up questions were tailored to the initial responses.

With participants' consent, we also examined their Facebook activity to determine their frequency of use, the type of information they post, and the types of interactions they have. Similar to prior work [14], we used participantobservation to interact with individuals on Facebook to illuminate the details in their social media use and enrich our data set. In our preliminary research, we found that the majority of Cubans who interact on social media do so through Facebook; therefore, we focused our online participant-observation on that site. In the consent form, participants were notified about this method and each interviewee agreed to become Facebook friends with the first author to facilitate our research. The first author created a private Facebook list that included participants and was only visible to her. This feed was monitored daily. The authors noted the frequency and types of posts by participants and tailored our questions based on these observations. This also allowed us to view demographic data via participants' profiles. We conducted brief followup interviews with participants via Facebook chat, enabling us to interact with them more frequently and ask them specific questions about their Facebook activity. The first author's Facebook friend list is private to protect our subjects' privacy.

Interviews were conducted in Spanish, English, and a mixture of both depending on the participant's preference. Interviews were transcribed and translated into English by the first author, who is fluent in Spanish. One researcher conducted thematic analysis [8] and performed qualitative coding. All authors discussed the codes and emerging themes throughout the coding process.

The United States and Cuba have a complicated history, and it is important that we reflect on our own relationship to this international situation. We draw from feminist social science research regarding researcher self-disclosure and reflexivity in an effort to be transparent [23]. Two authors are bilingual Cuban Americans, both fluent in Spanish. The first author comes from Cuban descent but was born and raised in the United States. She has traveled to Cuba twice and is familiar with the culture and customs through lived experience and regular contact with friends in the country. Access to participants was facilitated by the language skills, cultural knowledge, and social network of the first author. The second author's brother and parents were born in Cuba, whereas she was born in the US She has traveled to Cuba once on an academic trip in which she briefly studied the medical and educational systems in Cuba, and is acculturated to Cuban culture and customs. For both the first and second author, this Cuban heritage brings with it a passionate sympathy for the plight of the Cuban people, which shapes all our work related to this topic. The third author is not of Cuban descent and speaks no Spanish, and has been able to balance discussions with an outsider's perspective. Our research meetings are conducted in a mix of Spanish and English when the third author is not present, and in English when the third author is participating.

Because all authors were born and raised in the US, our research approach naturally stems from our background living in a country that highly values democratic principles and freedom of speech. All three authors share the conviction that Cuba should adopt a greater openness to the rest of the world. Interestingly, we often disagree on how best to achieve that openness, since we come from opposite ends of the US political spectrum. The political diversity within our team is a source of intellectual depth as we continually challenge one another's assumptions. These values and commitments shape the questions we ask and 
answers we hear. However, this research is not intended to take a political stance or advocate for a specific cause. Rather, we hope this research helps to communicate the lived experiences and desires of our participants, rather than we as researchers speaking for them.

\section{FINDINGS}

To explore the impact of Internet access on the daily life and worldview of early IT adopters in Cuba, we detail how Cubans access the Internet and how this shapes their usage. Additionally, we identify the most important aspects of Internet use for Cubans as reported by participants: connecting with friends and access to information. We describe how Cubans use the most popular site in Cuba, Facebook, and what they post online. Finally, because this study serves as a baseline for an ongoing study of how increased Internet access affects Cuba, we discuss participants' feelings regarding the future of the Internet in Cuba.

\section{The State of the Internet in Cuba}

Current Internet penetration in Cuba is estimated between 5 to $25 \%$, with only $5 \%$ of the population having full access to the Internet. The rest only have limited Internet access that includes a national e-mail system, pro-government websites, and some other services [39]. Therefore, if one has email access, whether by smartphone or computer, this does not mean that they have Internet access. Participants reiterated this, saying that the majority of their friends and acquaintances do not have Internet access and they considered themselves among the minority.

None of the participants regularly accessed the Internet in cyber cafes due to slow bandwidth and high cost. Access costs about US $\$ 4.50$ an hour and the average Cuban earns the equivalent of US \$20 per month [43]. Few people have Internet access at home and none have access on their cell phones. Though, as of spring 2014, a few have access to an email service on phones called Nauta, costing $\sim \$ 1.20$ per megabyte [43]. Three of our twelve participants (P1, P9, and P11) have access to email on their phones. However, the service is slow and unreliable.

Since the normalization of relations with the US was announced, changes in Internet access have been minimal. In February 2015, Cuban officials announced a promotion for state-run cyber cafes allowing users to access the Internet for two hours and 16 minutes for $\$ 5$ (instead of the normal $\$ 4.50 /$ hour) [3]. However, the promotion ran until April 10, 2015, and was still prohibitive, considering the average monthly salary in Cuba.

Internet continues to be expensive. [This new price] is half of the first monthly salary that I had when I started working. - Pl

\begin{tabular}{|c|c|c|c|c|c|}
\hline & Age & Sex & Occupation & $\begin{array}{l}\text { Inter- } \\
\text { view } \\
\text { Medium }\end{array}$ & $\begin{array}{l}\text { Interview } \\
\text { Lang. }\end{array}$ \\
\hline $\mathrm{P} 1$ & 24 & $\mathrm{~F}$ & $\begin{array}{l}\text { Radio } \\
\text { Broadcaster } \\
\text { and English } \\
\text { Interpreter }\end{array}$ & $\begin{array}{l}\text { Facebook } \\
\text { Chat }\end{array}$ & $\begin{array}{l}\text { Spanish } \\
\text { and } \\
\text { English }\end{array}$ \\
\hline $\mathrm{P} 2$ & 23 & $\mathrm{~F}$ & $\begin{array}{l}\text { Computer } \\
\text { Engineer }\end{array}$ & $\begin{array}{l}\text { Facebook } \\
\text { Chat }\end{array}$ & Spanish \\
\hline P3 & 48 & $\mathrm{M}$ & $\begin{array}{l}\text { Electrical } \\
\text { Engineer }\end{array}$ & $\begin{array}{l}\text { Facebook } \\
\text { Chat }\end{array}$ & English \\
\hline $\mathrm{P} 4$ & 30 & M & Metrologist & $\begin{array}{l}\text { Facebook } \\
\text { Chat }\end{array}$ & $\begin{array}{l}\text { Spanish } \\
\text { and } \\
\text { English }\end{array}$ \\
\hline P5 & 26 & $\mathrm{M}$ & $\begin{array}{l}\text { Graduate } \\
\text { Student }\end{array}$ & Skype & Spanish \\
\hline P6 & 31 & M & Professor & $\begin{array}{l}\text { Facebook } \\
\text { Chat }\end{array}$ & $\begin{array}{l}\text { Spanish } \\
\text { and } \\
\text { English }\end{array}$ \\
\hline P7 & 31 & $\mathrm{M}$ & Economist & Phone & Spanish \\
\hline P8 & 26 & $\mathrm{M}$ & Programmer & $\begin{array}{l}\text { Facebook } \\
\text { Chat }\end{array}$ & Spanish \\
\hline P9 & 24 & $\mathrm{~F}$ & $\begin{array}{l}\text { English and } \\
\text { French } \\
\text { Interpreter }\end{array}$ & Email & Spanish \\
\hline P10 & 22 & $\mathrm{~F}$ & Student & Email & English \\
\hline P11 & 26 & $\mathrm{M}$ & Programmer & $\begin{array}{l}\text { Facebook } \\
\text { Chat }\end{array}$ & Spanish \\
\hline P12 & 60 & $\mathrm{M}$ & $\begin{array}{l}\text { Radio } \\
\text { Station } \\
\text { Program } \\
\text { Director }\end{array}$ & Email & Spanish \\
\hline
\end{tabular}

Table 1 - Description of Participants

In March 2015, Cuba allowed the launch of the first free, public Wi-Fi service in the country. This service is run by a prominent artist, Kcho, which costs the artist approximately $\$ 900$ per month [45]. With many Cubans attempting to use the service, the speed is prohibitively slow, seeming more like a symbolic change rather than a practical one. Each participant we spoke to had Internet access at work or at school. Of those with access at school, it was limited to a 
couple of hours per week. P5 accessed the Internet occasionally from the home of a friend who is a foreigner and has been granted a license to have Internet in his home. Three of our participants, P6, P10 and P12, also had limited access to the Internet at home.

I use the institutional account of a family member who works in the cultural sector and it's mainly used for email service, but it additionally allows access to selected sites (usually .cu sites, Wikipedia, some foreign press). I have my own account through the University, which also provides email service, but its additional access is more limited (only sites directly related to the University). - P6

The Internet access that I have is extremely limited. We have it in school, but it's a limited quota that doesn't work for everything. Additionally, certain sites like Facebook are only accessible at certain hours a day. Apart from that, the Internet that I have [at home] is one that I buy for a few hours per week, depending on what they allow me. - P10

Because hardly any Cubans have Internet access at home, it is not surprising our participants reported mainly using the Internet for work or school, which affected the framing of our conversations with them. The three participants who had limited access at home still stated that they mainly use it either for school or work. In the initial stages of our interviews, interviewees discussed their Internet use in terms of how it has affected their jobs or studies. Internet speeds at workplaces and universities are often faster than those in individuals' homes, but they are still restrictive.

Computer hardware at home was purchased either during international travel or on the black market. Some home hardware was surprisingly up-to-date, while other hardware was cobbled together from quite old components. We do not have data on the age of computers used at work or school or how they were obtained.

Although pornography is often credited as a driver of demand for Internet access [32], our participants pointed out that they were unable to access pornography in Cuba or shop online. Other news articles have confirmed the inability to access pornography in Cuba, pointing out that even trying to access a pornographic site can lead to the cancellation of web services [51]. It has also been reported that Internet users must sign a contract that they will not look for pornographic content [24] and there can be harsh consequences for being caught with pornography.

Interviewer: When did you first get an email address? P4: In the university... after that they cut off the Internet for students

Interviewer: Do you know why they cut it off?

P4: Because they discovered that one student had pornography and used the connection to upload photos and took advantage and they took away the Internet for the first three years for all the majors. The last two years we had Internet two times per week for only 10 minutes.

Unlike other studies regarding the introduction of the Internet to communities [38], we find that because this type of content is blocked or inaccessible in Cuba, participants reappropriate the Internet in different ways. However, participants still use the Internet for entertainment purposes, which is consistent with other findings on early Internet access in communities [38]. Participants admitted to accessing Facebook or Google for personal reasons when possible.

[Facebook] is blocked for the majority of my coworkers but now they let me have it so that I can contact counterparts and so that I can use it for work... the majority of the time I use it for my own personal things. - P4

\section{Regulations and Restrictions}

Until now the government has not been interested in the community having access to the Internet. They use the justification that it's expensive, that there's not bandwidth, that people are not ready for that, it's as if the people were stupid. - P3

As opposed to relying heavily on content censorship like other countries with tightly controlled Internet access, such as China or Iran, the Cuban government also controls the spread of information through high cost and slow bandwidth [6]. Participants felt their Internet use was restrictive due to slow access, high costs, and blocked content. This trend continued throughout our interviews, serving as the main challenge to recruiting participants. All participants reported that there are things they would like to do on the Internet but are unable to, due to slow connection speeds and high costs.

I always try to access Facebook to have contact with some person. But it's very complicated because the connection is extremely slow. So, a lot of times, I can be talking with someone and, boom, the connection drops. And I have to wait to connect again...everything is a hassle. - P5

I have access in my workplace, but it is a very slow Internet, where you can't watch videos and sometimes not upload photos. - P1

In addition to cost and speed, content blocking was also a factor that limited access for participants. Some participants stated that sites were blocked because of other companies or countries limiting access to Cuba.

There are many sites where there is technical information and articles online that we are forbidden from accessing because we live in Cuba. - P3 
There are lots of things that I want to do on the Internet but can't. Up until recently, there were many services in Google that weren't available in Cuba. For example, Google analytics. Similarly, Skype doesn't work in Cuba. I would like to be able to use it to talk to many people but I can't. I would like to be able to edit my Facebook profile more than once per week or be able to use Netflix to watch the series that I like but I can't do that, either. - P10

Regardless of restrictions, the Cuban technological community (which we define as individuals who have access to technological tools) has found creative workarounds to government blockades [7,35]. For example, two participants mentioned revolico.com, a virtual marketplace where individuals sell goods and services from computer repair to USBs. It should be noted that the exchange of money and goods, however, takes place inperson and no money is exchanged online. Rather, revolico.com acts more like a forum or message board. Additionally, an "offline" Internet has formed in Cuba in which citizens distribute media through USBs called "packages" [7]. During the first author's travels in Cuba, she encountered this practice among every young person with whom she spoke. Most neighborhoods have a person who sells various packages that contain content like YouTube videos, mp3s, movies and news.

People here share information by way of hard drives...It's what people call the "Weekly Packet" that's around I terabyte. They sell it very cheap. They sell a copy of the series, movies, etc. - P3

In addition to selling Internet content via hard drives and USBs, some individuals access content and technological tools through other non-traditional means:

In Cuba they exploit more technology that what most would imagine. All software that is used is pirated and we all have access to them without fear of penalty or problems with the law. Although there isn't Internet, the average PC user [in Cuba] does much more than the regular user out in the world. Format memories, reinstall operating systems, use professional programs like Adobe Suite or others that are really expensive are easily accessible in Cuba. This is a great paradox for these times. - P4

Sometimes you have to find ways around stuff. A trick I use for example: At home I can do the basic search of Google, but not follow links, so sometimes I feed the search something I'm looking for just to see where it might be available and then go somewhere else to get it. People can sometimes answer messages on Facebook by replying to the email notification... You gotta be crafty sometimes.. - P6

Some people sneak around hotels to get Wi-Fi access using password breaking...People share information in this city through an "intranet" made between people with incentive, off the record, and who have bought their own equipment, routers, etc., that they interconnect, over more than $30 \mathrm{~km}$ in the city. Sometimes groups of young people put a router in a building and connect the others with cables or wireless connection and they share the connection to exchange movies, documentaries, and even play. But everything occurs inside the bubble. - P3

Such resourcefulness is common practice in countries with Internet blocking and access limitations [40]. Although workarounds are possible in Cuba, the activity occurs, as P3 put it, "inside the bubble," meaning that few people are able to access the Internet to connect with individuals or information outside of Cuba.

\section{Internet Use}

"Things don't happen like you think they happen. For the average Cuban, the Internet is Facebook. Perhaps you all see the Internet differently. For us, the Internet is Facebook, Facebook, Facebook." - P7

Regardless of the high barriers to access, participants still managed to get online, mainly through workplaces. In addition to sites that participants had to access for work purposes, all participants reported that Google or Facebook were among their favorite sites, with Facebook being reported as the most used site. Our findings are consistent with a recent survey conducted in Cuba that reports that 91\% of Cubans with Internet access use Facebook [59]. When asked what they use the Internet for, each participant said to connect with friends and access information, both of which will be explored further in the following sections.

\section{Connecting with friends}

Being able to connect with friends offers a large impact on Cubans with Internet access. While this may seem obvious (doesn't everyone use the Internet for this?), for Cubans it is of particular importance. Nearly every Cuban has family members outside of Cuba and many have not been in contact with them for years. As P3 told us, "sometimes they don't even allow you to use regular mail to write to your closest relatives living abroad." In addition, phone calls to people outside of Cuba are expensive. Therefore, the Internet, particularly Facebook, is opening new communication modes for Cubans.

In my university there were people from different provinces and once we graduated Facebook became like our place for reunions. A lot don't have telephones and we're able to stay up to date through this medium. - P2

With the Internet, I finally have contact with my cousins and my family in Florida. - P5

Our participants typically use the Internet to connect with people they already know. However, as stated earlier, 
several participants said that the majority of their friends do not have Internet access, limiting the number of people in one's online social network who are also co-located.

\section{Information access and collaboration}

While connecting with friends is important to Cubans, the ability to access information online is perhaps even more crucial. Similar to other studies on Facebook use in lowaccess regions [55], all participants spoke with optimism and a somewhat utopian outlook about using the Internet and SNS for information access.

[The Internet] has affected me positively, because I'm kept updated on the global agenda, things that many times the press or news here doesn't inform us. $-P 2$

In reality, the access to so much information, has been good...I've resolved complicated technical problems thanks to the information and help forums. - P3

Because Internet penetration remains low in Cuba, communities use collaborative efforts to retrieve and share information. As P5 explained, "A lot of the news that you find on the Internet you can hear from a friend who heard from a friend who heard from another friend." In Cuba, news primarily continues to travel through face-to-face social networks. People with Internet access often retrieve content for others and disseminate information to their local communities. Participants described the ways in which they use the Internet to collaboratively retrieve information and how they ask for information retrieval from others when their access is limited.

Mostly [I share] news on current events or entertainment. Occasionally academic knowledge, too. Like having the odd neighbor's child needing some information for homework. Among friends, it's a regular thing. - P6

Since the revolution, the Cuban media has been controlled by the government, limiting the amount of information that Cubans receive about the outside world as well as their own community [7,35]. As a result of increased access to information via the Internet, participants discussed the Internet and social media in terms of it affecting their perspectives and perceptions of reality.

[The] Internet always allows me to see that there is so much I don't know, so much that I am not aware of. - P10

The most important thing [about the Internet] is to have other sources of information from other points of view and perspectives different from those of our country, which has a complacent and biased press. - P3

Participants spoke about their lack of information access as something that hampers Cuba's development, amplifying their sense that they are isolated from the rest of the world.
Individuals are eager to redefine what it means to be Cuban and to go beyond the traditional revolutionary identity that the state has perpetuated during the past half-century [48]. Participants reported feeling as though information had been hidden from them and that there were gaps in their knowledge about the state of their world. Therefore, individuals are eager to have access to more diverse information and opinions.

Normally, what we consume is what they distribute in Cuba, the information they give us. And we need another version of reality to be able to confront what we ourselves think.... - P7

My vision has changed, because now I'm not so vulnerable to what they want to me believe; I know with my own eyes what is reality. $-P 1$

Although participants spoke about the importance of having information access via the Internet, some individuals described a concern that Cubans may misuse it.

Many that have access don't use it for purposes that it really should be used for and use it more for either recreational purposes and other things...The Internet is for work, to increase knowledge, to communicate which is also very important, but not for playing. - P12

The Internet is necessary but dangerous. Necessary because Cubans need to feel like a part of the world and enjoy all of the facilities offered by the Internet.... Dangerous because Cubans have never had the power of the Internet in their hands (to call it that) and can get carried away by all of the falsehoods that are published there. - P2

Among our participants, only P2 and P12 hinted at concerns about possible negative implications of Internet technology. For participants coming from a world where information is typically officially vetted, access to unfiltered information is a paradigm shift.

\section{What do Cubans Post Online?}

With their consent, we also observed each participant's Facebook activity during the month of April 2015. Similar to research in other countries [55], participants' Facebook use is clearly mediated by access limitations. All Facebook activity by participants occurred on a weekday between the hours of 6 a.m.-5 p.m. while at their jobs. Only P6 posted outside of this timeframe because he had increased access during his international travels. Unsurprisingly, participants with faster Internet connections and regular access posted more often on Facebook than those without access.

Selfies and pictures of friends and family are popular content for Facebook posts. However, due to access barriers, uploading pictures does not occur as often as it might if connection speeds were faster. Instead, participants 
often rely on sharing content from Facebook pages of friends who are able to upload images. Only three participants (P1, P6 and P9) posted photos during the month of April. P6 uploaded these photos while outside of Cuba, and both P1 and P9 said that they have good access at work and were able to upload photos. P1's posts were all pictures of herself and friends, which she tagged so that the pictures would appear on their profiles. Nine participants had photos of themselves added to Facebook by others. P1 explained that users in Cuba rely on those with faster and more frequent Internet access to help maintain their Facebook presence. Similar to the collaborative efforts used to retrieve information, some individuals rely on friends outside of Cuba to help them maintain their social media presence. As opposed to the average Internet user in the US, in Cuba connections to others and collaboration are vital parts of maintaining an individual online presence. P10 is a photography student and maintains a Facebook page with images of Cuba as part of her academic studies. However, she must rely on her boyfriend who lives outside of Cuba to upload the photos by logging into her account on her behalf.

I know how to use [Facebook] for things that I need, like the page for my photographs, but I've had to resort to other forms that my photos arrive on the page, I can't be the one who uploads them, who responds to the comments, the messages that people leave, etc. and that, honestly, leaves a bad taste in my mouth, like there is a piece of the process that I am not seeing. - P10

The authors also made note of the content on participants' Facebook walls to determine what content originated from Cuba versus other countries. Table 2 includes the number of links posted on Participants' walls by themselves and others during the month of April 2015 (this does not include pictures uploaded by participants or their friends). People in any country have different SNS usage patterns, and Cuba is no exception. As evident from Table 2, participants exhibited different behavior patterns in their Facebook use. Although all participants spoke about the importance of access to information originating outside of Cuba (particularly in terms of educational or informational material), all of the content originating from outside of Cuba was for entertainment purposes.

Research shows that some Cubans use the blogosphere as an alternative public sphere $[13,19,25]$; however, our participants do not seem to use Facebook to mobilize, speak their opinions, or ask questions or favors of their audience. Because most of our participants' friends and family in Cuba are not on Facebook, the majority of their social capital is based on in-person connections, which may explain why participants do not use Facebook to gather support from their community in terms of seeking favors or making requests. Additionally, the only political discourse on Facebook that we observed dealt with the normalization of relations between Cuba and the United States, and each one of these posts were made by other Facebook users who tagged some of our participants (and therefore the post appeared on their walls). The majority of our interviews confirmed our observations.

Opinions may be expressed, but people rarely use social networks as platforms...I don't know if they're guarded. Maybe. But it's mostly a matter of what is simply cool or not cool to post in your circle. I don't think it's a Big Brother thing. - P6

Although P6 attributes the type of content posted to social norms of one's network, there may be other factors influencing participants' use. When considering Cuba's history in the past 50 years and the fact that political dissidents have been imprisoned for openly defying the government, it is not surprising that participants do not use Facebook to share opinions on controversial topics. During our interview, P12 discussed negative results from something that he posted on Facebook.

On one occasion, I fell into the trap of saying something that my bosses didn't like and I almost lost my access. Since that day, I've tried to dedicate myself to only what concerns me and the path I walk on. - P12

When talking about the type of material she posts on Facebook, P1 said, "We could talk about politics, but I hate politics so we never talk about anything like that." This statement is indicative of an observed mutually reinforcing trend. Since it's a sensitive topic, participants may say that they do not post about politics (or other controversial topics) as a way to protect themselves. As a result, others in their community refrain from posting similar content in an effort to maintain social norms. However, there are indications that there may be shifts underway in Cubans' use of Facebook, notably through the artist community. P10 is studying photography for her undergraduate degree and has created a Facebook page to share her photos. In this way, she feels as though she is showing the outside world what Cuba is like. However, she has to go to great lengths to actually post the images, which, as mentioned previously, may be one of the reasons more people do not post images. Through the creation of a Facebook page for her photos, her use of Facebook has become more varied:

I joined Facebook in the first year of my job...it appeared to me like a good way to maintain contact with a lot of people that were no longer in Cuba. It's for that reason that I use Facebook. Although, ultimately, since I created a page for my photos, I now also use it to show my work, to publicize it and share it with more people, so it's allowed me to get to know many opinions about it and learn some things, too. P10 


\begin{tabular}{|c|c|c|c|c|}
\hline Participant & $\begin{array}{l}\text { Links } \\
\text { from } \\
\text { Cuba }\end{array}$ & Description & \begin{tabular}{|l} 
Links from \\
other \\
countries
\end{tabular} & Description \\
\hline P1 & 3 & $\begin{array}{l}2 \text { links to advertisements posted by } \\
\text { Cuban Facebook pages. } 1 \text { link to Cuban } \\
\text { newspaper article about cultural event } \\
\text { in Cuba. }\end{array}$ & 2 & $\begin{array}{l}1 \text { blog post from outside of Cuba about } \\
\text { cultural event in Cuba. } 1 \text { link to YouTube } \\
\text { music video. }\end{array}$ \\
\hline $\mathrm{P} 2$ & 0 & & 63 & $\begin{array}{l}18 \text { links to humorous/uplifting memes from } \\
\text { other Facebook pages. }\end{array}$ \\
\hline P3 & 1 & 1 link to GoFundMe page. & 0 & \\
\hline $\mathrm{P} 4$ & 1 & $\begin{array}{l}1 \text { link to Cuban newspaper article about } \\
\text { cultural event in Cuba. }\end{array}$ & 1 & $\begin{array}{l}1 \text { blog post from outside of Cuba about } \\
\text { cultural event in Cuba. }\end{array}$ \\
\hline P5 & 0 & & 4 & $\begin{array}{l}1 \text { link to blog post from the US about Cuba. } \\
1 \text { link to humorous YouTube video. } 1 \text { link to } \\
\text { inspirational quote. } 1 \text { link to sports article. }\end{array}$ \\
\hline P6 & 0 & & 3 & $\begin{array}{l}2 \text { links to memes. } 1 \text { link to European soccer } \\
\text { article. }\end{array}$ \\
\hline P7 & 0 & & 0 & \\
\hline P8 & 0 & & 0 & \\
\hline P9 & 5 & $\begin{array}{l}5 \text { links to news articles about Cuba } \\
\text { from Cuban newspapers. }\end{array}$ & 25 & $\begin{array}{l}23 \text { links to humorous/uplifting memes. } 2 \\
\text { animal videos from other Facebook pages. }\end{array}$ \\
\hline $\mathrm{P} 10$ & 1 & $\begin{array}{l}1 \text { advertisement posted by Cuban } \\
\text { Facebook page. } 1 \text { shared photo from her } \\
\text { company's Facebook page. }\end{array}$ & 2 & $\begin{array}{l}1 \text { link to meme. } 1 \text { link to YouTube music } \\
\text { video. }\end{array}$ \\
\hline P11 & 0 & & 0 & \\
\hline P12 & 18 & $\begin{array}{l}18 \text { links to local Cuban sports news } \\
\text { related to his job as sports journalist. }\end{array}$ & 0 & \\
\hline
\end{tabular}

Table 2 - Origins of Links on Participants' Facebook Walls during April 2015

Unlike studies regarding Facebook use in the US [28], participants generally do not use Facebook for mobilization requests. However, there was one exception. On April 13, 2015, P3 shared a public post promoting a GoFundMe page for his son's local band. This is unlike any other post observed during this research and the first post by a participant who was making a request of the Facebook community. P3 said that a friend in the US helped to create the page and is accepting funds and equipment donations on behalf of the band. This one incident is not significant in itself; however, it will be interesting going forwards to observe whether Cubans' use of Facebook begins to evolve.

In addition to the examples from P10 and P3, other participants mentioned that, with increased Internet access, they think their Internet use will change:

[In the future] I think that people will go about adopting the Internet in their daily jobs just like has already happened in all the other countries in the world and that in this moment a lot of new and good things will arise because a lot of artists, painters, musicians, designers, etc. that would be able to share their work and people would get to know [them] through this route. - P11

\section{Future of Cuba's Internet}

We spoke with participants about the future of Cuba's Internet. More generally, participants spoke about their frustrations with feeling that their country is behind economically, and they hope that change is coming to their country. They see the Internet as a potential catalyst for that change. Participants explained that the Internet is needed for education and information access in order to improve economic development and continue to educate their population.

In academia [the Internet] is an absolute must, and much is lost or not developed by not having better access to information, tools and skills. As a teacher I notice that every day. The same applies to almost every level of society. 
Any profession can benefit from the Internet. The worldview would change drastically too. For the better, I think. - P6

I think the changes we need the most are Internet for everyone, the reconstruction of the cities, and the establishment of some food companies. - P1

\section{DISCUSSION}

Mark et al. [29] found that Iraqi citizens during war time used social media to help them be more resilient in a number of ways: reconfiguring social networks, self organization, redundancy, proactive practices, and repairing trust in information. We observed only one of these practices among our participants in Cuba: repairing trust in information. Our participants all reported using social media to obtain information that would not otherwise be accessible to them. It is common practice to share information with others who do not have access. Through this mechanism, information access for a small minority has a broader impact.

We did not see social media used in any of the other ways researchers observed in Iraq. For example, so few people have access in Cuba that people typically don't meet new people over social media. Our participants used social media to connect with family and existing friends. Many of the creative ways that Iraqis [29], Mexicans [33], and others use social media for resilience depend on widespread access to cell phones and the Internet. The lack of these factors in Cuba hampers the ways in which Cubans appropriate ICTs.

Our participants mainly used the Internet for relationship maintenance and for entertainment. This is similar to what Sandvig et al. [38] observed when Internet access was first introduced to a Native American reservation in the US. In his "cute cat theory of the Internet," Ethan Zuckerman argues that entertainment applications of IT are often a first step towards more serious uses. Further, under conditions of censorship, large volumes of entertainment use can help camouflage more controversial uses [58]. In fact, we can characterize the current state of the Internet in Cuba as "pre-cat," because bandwidth limitations mean that Cubans generally cannot yet engage in many of the entertainment applications observed by Sandvig and Zuckerman. Further, Zuckerman posits that it's more difficult for countries to block large sites, like Facebook, that are used both for controversial conversations and for sharing cute pictures of cats. As we have shown, Cubans who have Internet access gravitate towards Facebook and report that the majority of their Internet activity occurs there. If access for Cubans increases, if it follows patterns elsewhere, this suggests that there will be increased use for entertainment and social purposes using richer media, followed by more "serious" uses longer term. Further, it also suggests that if we wish to reach out to help Cubans with their information needs, it might be advantageous to leverage Facebook, since our users are already using that platform, and it may be less likely to be censored.

Our participants have rather utopian hopes for the introduction of Internet technology into Cuba. We observed only glimpses of skepticism-for example, concerns that people will find information online that isn't true. None of our participants expressed any concern that Internet access might change the pace of life in Cuba. P1 visited the US, and found the pace of life unpleasant:

Before [I visited] I thought the US was a paradise, the best in the world!!! And it's true that at the beginning you are in awe of the amount of development and cleanliness, but that life [in the US] is so hurried/rushed and with so little time, that I can't say that I like it completely. - PI

Researchers in the developed world suggest that our connectedness may be a key cause for the increased pace of life [46,50]. Going forward, it will be interesting to see whether the pace of life in Cuba increases, and how our participants feel about those changes. We plan to follow up with our participants regularly over the next few years, and will track the ways in which their beliefs and habits change. It is possible that dramatic changes will take place over a relatively short period of time. If so, we are hopeful that our participants will be in a unique position to reflect on those changes.

\section{LIMITATIONS}

Conducting research on Internet use in Cuba is made complicated by limitations on that use-we are exploring a limited medium by means of that same limited medium. We began with initial contacts established during a visit to Cuba, and used snowball sampling to make contact with additional participants. Consequently, our sample of Cuban Internet users is not representative. Additionally, we must note a self-selection bias-we spoke with Cubans who were willing to speak with us. It is possible that Cubans who are willing to be interviewed by an American may have systematic differences in values from those who are not.

More broadly, the group of Cubans who have Internet access is not representative of the Cuban population. As we have noted, they are an elite sub-group. It is possible that as more typical groups of Cubans gain access, their use patterns and the values they put on that use may be different.

Another limitation is the interview medium itself. Given the difficulties of obtaining Internet or phone access, we allowed our participants to select the way they would participate in the interview. As we note in Table 1, two interviews were conducted by voice communication, seven by online chat, and three by email. Research on interview technique suggests that higher bandwidth channels of communication provide richer information, and email 
interviews are impoverished compared even to those conducted via text chat [12]. We mitigated some of the limitations of email interviews by having iterative conversations over time with those participants.

It is both a limitation and a feature of this work that our data was conducted at one particular moment in time - the moment when potential dramatic changes had been announced but no actual changes seemed yet evident. The situation is dynamic. In future work, we would like to track how the situation changes over time. We would also like to travel to Cuba to conduct additional interviews in person.

\section{CONCLUSION}

Use of social media by early adopters in Cuba defies simple categorization. In many ways it seems like an example of ICT in the developing world-except with an extremely high literacy rate. It seems a bit like ICT under state censorship in China-except the censorship in Cuba is largely accomplished through low bandwidth and access restrictions rather than blocking software. It serves as an intriguing contrast for researchers studying Internet use in other parts of the world.

A growing number of international businesses are beginning to operate in Cuba. For example, Netflix announced its entry to Cuba in February 2015 [20], and AirBnB started offering lodgings in Cuba in April 2015 [57]. For members of the CSCW community directly involved with Cuba, this research should be of practical use.

The dominance of Facebook over all other social networks and websites in Cuba surprised us. As P7 comments, "For the average Cuban, the Internet is Facebook." In a context in which most people do not have consistent access to any kind of communications technology including telephone, intermittent access to Facebook is used for basic communication for both work and socializing. It is used as a central communications channel both with others in Cuba and to reach people abroad. Participants with lower access reported that they rely on others to help maintain their Facebook presence, further highlighting the importance of collaborative efforts to use Internet tools. The majority of Facebook posts by participants dealt with entertainment content or personal pictures. The dominance of Facebook in current Internet use in Cuba sets an intriguing context for Facebook as a company and for other companies beginning to move into this space.

Few places remain in the world where Internet access is as limited as it is in Cuba currently. If Internet technology is introduced into Cuba rapidly, what happens next will constitute a kind of natural experiment. These findings serve as a baseline for future work.

\section{FUTURE WORK}

The goal of this work was, first, to understand the current situation in Cuba to establish a baseline of Internet use there. We plan to follow up with our participants at intervals over the next few years.

Our second goal was to conduct user-centered design of possible CSCW interventions to help the people of Cuba. Based on our findings, in future work, we are exploring the potential for creating a crowd-sourced information system for Cubans. Our research has shown that Cubans are eager to access information from outside their country but are limited by restrictions such as content blocks, high access costs, and time limitations. Access to email is more widespread than access to the Internet more generally. As we have shown, Cubans are already using collaborative methods to access and share information.

Drawing from these findings, we plan to develop an online group that encourages exchanges between individuals living in Cuba and the rest of the world. This group will allow individuals in Cuba to send information requests to volunteers living outside of Cuba who have access to a wider variety of information at much lower costs. We envision a combination of crowd-sourced information retrieval and cultural exchange.

We found that Cubans are eager to show outsiders what life is like in Cuba. Consequently, the information service will be two-way, allowing people outside Cuba to ask questions of Cuban citizens. Making the system two-way will also help keep implicit power relationships more nearly equal, fostering a spirit of mutual respect and desire for increased understanding.

To build an initial version, we will prototype with existing technologies [21] using a combination of Facebook groups and email. Accessibility is a key goal. We aim is to make the system workable with the Internet access Cubans have now, and scale gracefully to remain useful if/when their access increases. Even if we encourage use of the group just for non-controversial topics, increased exposure to the rest of the world has the potential to be transformative. We plan to begin field-testing a low-fidelity prototype later this year.

We expect the information retrieval aspect of our group to be useful for only a short period of time, after which more Cubans will have direct Internet access. Through this work, we hope to help our Cuban participants during this time of transition. In addition to providing our participants with information, we also aim to build relationships between Cubans and participants outside Cuba. By observing the activity in the group, we will gain insights into the ways in which information access via the Internet can affect the culture and beliefs of a literate but isolated population. 


\section{ACKNOWLEDGEMENTS}

Thank you to our participants for being involved in this research. We also thank the reviewers for their valuable feedback. This work is supported by NSF II-1552364.

\section{REFERENCES}

1. Sheetal K Agarwal, Arun Kumar, Amit Anil Nanavati, and Nitendra Rajput. 2009. Content creation and dissemination by-and-for users in rural areas. Proceedings of the International Conference on Information and Communication Technologies and Development (ICTD '09), IEEE, 56-65. $\mathrm{http}: / / \mathrm{http} / /$ ieeexplore.ieee.org/xpls/icp.jsp?arnumber $=5$ 426702

2. Jenny C. Aker and Isaac M. Mbiti. 2010. Mobile Phones and Economic Development in Africa. SSRN Electronic Journal. http://papers.ssrn.com/abstract=1693963

3. Associated Press. 2015. Cuba Cuts the Price of Internet Access. NBC News. Retrieved May 12, 2015 from http://www.nbcnews.com/news/world/cuba-cuts-priceinternet-access-n308591

4. Ashraf M. Attia, Negris Aziz, Barry Friedman, and Mahdy F. Elhusseiny. 2011. Commentary: The impact of social networking tools on political change in Egypt's "Revolution 2.0." Electronic Commerce Research and Applications 10, 4, 369-374. http://www.sciencedirect.com/science/article/pii/S1567 42231100024X

5. Peter Baker. 2014. U.S. to Restore Full Relations With Cuba, Erasing a Last Trace of Cold War Hostility. New York Times. Retrieved April 29, 2015 from http://www.nytimes.com/2014/12/18/world/americas/u s-cuba-relations.html?_r=0

6. Guy Baron and Gareth Hall. 2014. Access Online : Internet Governance and Image in Cuba. Bulletin of Latin American Research, 1-16. http://doi.org/10.1111/blar.12263

7. Ellery Roberts Biddle. 2013. Rationing the Digital: The Politics and Policy of Internet Use in Cuba Today. Internet Monitor Special Report Series 1. http://doi.org/10.2139/ssrn.2291721

8. Virginia Braun and Victoria Clarke. 2006. Using Thematic Analysis in Psychology. Qualitative Research in Psychology. http://www.tandfonline.com/doi/abs/10.1191/14780887 06qp063oa

9. CIA. 2015. CIA World Fact Book: Country Comparisons: Literacy. Retrieved July 24, 2015 from https://www .cia.gov/library/publications/the-worldfactbook/fields/print_2103.html

10. Karen DeYoung. 2015. U.S. and Cuba set to formally reestablish diplomatic relations - The Washington Post. Washington Post. Retrieved July 24, 2015 from https://www.washingtonpost.com/world/nationalsecurity/us-cuba-prepare-to-re-establish-diplomaticrelations/2015/07/17/5304d4f6-2cc4-11e5-bd33395c05608059_story.html

11. Jill P Dimond, Michaelanne Dye, Daphne Larose, and Amy S Bruckman. 2013. Hollaback!: The Role of Collective Storytelling Online in a Social Movement Organization. Proceedings of the SIGCHI Conference on Computer Supported Collaborative Work and Social Computing (CSCW'13), 477-490. http://doi.org/10.1145/2441776.2441831

12. Jill P. Dimond, Casey Fiesler, Betsy DiSalvo, Jon Pelc, and Amy S. Bruckman. 2012. Qualitative data collection technologies. GROUP '12, ACM Press, 277. http://dl.acm.org/citation.cfm?id=2389176.2389218

13. Paloma Duong. 2013. Bloggers Unplugged: Amateur Citizens, Cultural Discourse, and Public Sphere in Cuba. Journal of Latin American Cultural Studies 22, 4, 375-397. http://doi.org/10.1080/13569325.2013.840277

14. Michaelanne Dye. 2011. La Vida Online: The Parallel Public Sphere of Facebook as Used by Colombian Immigrant Women in Atlanta. Master's Thesis. Georgia State University, Atlanta, GA. http://scholarworks.gsu.edu/anthro_theses/52/

15. Pamina Firchow. 2013. A Cuban Spring? The Use of the Internet as a Tool of Democracy Promotion by United States Agency International Development in Cuba. Information Technology for Development. http://www.tandfonline.com/doi/pdf/10.1080/02681102 .2013 .793119

16. Lorenzo Francheschi-Bicchierai. 2014. The Internet in Cuba: 5 Things You Need to Know. Mashable.

Retrieved May 12, 2015 from http://mashable.com/2014/04/03/internet-freedomcuba/

17. Freedom House. 2014. Freedom on the Net: Cuba. Retrieved April 29, 2015 from https://freedomhouse.org/report/freedom-net/2014/cuba

18. Alexeis García Pérez. 2011. Knowledge behind barriers: IT access as an enabler of Cuban development. Information Technology for Development $17,1,81-88$. http://doi.org/10.1080/02681102.2010.509713

19. Marie Laure Geoffray. 2013. Internet, Public Space and Contention in Cuba: Bridging Asymmetries of Access to Public Space through Transnational Dynamics of Contention. Berlin. http://www.desigualdades.net/Resources/Working_Pap er/42_WP_Geoffray_Online.pdf

20. Jessica Glenza. 2015. Netflix launches $\$ 7.99$ service for Cuba despite average wage of $\$ 17$ a month. The Guardian. Retrieved July 24, 2015 from 
http://www .theguardian .com/world/2015/feb/09/netflix -launches-streaming-service-cuba

21. Catherine Grevet and Eric Gilbert. 2015. Piggyback Prototyping : Using Existing, Large-Scale Social Computing Systems To Prototype New Ones. Proceedings of the SIGCHI Conference on Human Factors in Computing Systems (CHI'15), 4047-4056.

22. Greg Guest, Arwen Bunce, and Laura Johnson. 2006. How many interviews are enough? An experiment with data saturation and variability. Field Methods 18, 1, 59-82. http://fmx.sagepub.com/content/18/1/59.short

23. Kathryn Herr and Gary L. Anderson. 2005. The action research dissertation: A guide for students and faculty. Sage.

24. Bert Hoffmann. 2003. El Desarrollo Cubano Ante el Reto de las Nueva Technologías de Información y Comunicación. In Cuba: reestructuración económica y globalización, Mauricio de Miranda Parrondo (ed.). Centro Editorial Javeriano, Bogotá, 295-328.

25. Bert Hoffmann. 2011. Civil Society 2.0?: How the Internet Changes State-Society Relations in Authoritarian Regimes: The Case of Cuba. German Institute of Global and Area Studies. http://doi.org/10.2139/ssrn.1763846

26. Shanthi Kalathil and Taylor C. Boas. 2001. China, Cuba, and the counterrevolution. First Monday. http://www.firstmonday.dk/ojs/index.php/fm/article/vie w/876/785

27. Joe Lamar. 2015. For Cubans, the struggle to supplement meagre rations is a consuming obsession. The Guardian. Retrieved July 26, 2015 from http://www.theguardian.com/world/2015/apr/24/cubans -food-struggle-rations-consuming-obsession

28. Cliff Lampe, Rebecca Gray, Andrew T Fiore, and Nicole Ellison. 2014. Help is on the way: Patterns of responses to resource requests on Facebook. Proceedings of the SIGCHI Conference on Computer Supported Collaborative Work and Social Computing (CSCW'14). http://dl.acm.org/citation.cfm?id=2531720

29. Gloria J. Mark, Ban Al-Ani, and Bryan Semaan. 2009. Resilience through technology adoption. Proceedings of the SIGCHI Conference on Human Factors in Computing Systems (CHI '09), ACM Press, 689. http://dl.acm.org/citation.cfm?id=1518701.1518808

30. Indrani Medhi-Thies, Pedro Ferreira, Nakull Gupta, Jacki O'Neill, and Edward Cutrell. 2015. KrishiPustak. Proceedings of the SIGCHI Conference on Computer Supported Collaborative Work and Social Computing (CSCW'14), ACM Press, 1670-1681.

http://dl.acm.org.prx.library.gatech.edu/citation.cfm?id $=2675133.2675224$
31. G. M. Mesher, R. O. Briggs, S. E. Goodman, J. M. Snyder, and L. I. Press. 1992. Cuba, communism, and computing. Communications of the ACM 35, 11, 27-ff. http://doi.org/10.1145/138844.138856

32. Daniel Miller and Don Slater. 2001. The Internet: An Ethnographic Approach. Berg Publishers.

33. Andrés Monroy-Hernández, Danah Boyd, Emre Kiciman, Munmun De Choudhury, and Scott Counts. 2013. The new war correspondents: The rise of civic media curation in urban warfare. Proceedings of the SIGCHI Conference on Computer Supported Collaborative Work and Social Computing (CSCW '13). http://dl.acm.org/citation .cfm?id=2441938

34. Tapan S. Parikh and Edward D. Lazowska. 2006. Designing an architecture for delivering mobile information services to the rural developing world. Proceedings of the 15th International Conference on World Wide Web (WWW'06), ACM Press, 791-800. http://dl.acm.org/citation.cfm?id=1135777.1135897

35. Larry Press. 2011. Past, Present, and Future of the Internet in Cuba. Association for the Study of the Cuban Economy 21. http://www .ascecuba.org/c/wpcontent/uploads/2014/09/v21-press.pdf

36. N Rangaswamy and E Cutrell. 2012. Anthropology, development and ICTs: slums, youth and the mobile internet in urban India. Proceedings of the International Conference on Information and Communication Technologies and Development (ICTD '12) 9, 2, 51-63. from http://dl.acm.org/citation.cfm?id=2160685

37. Nimmi Rangaswamy, G. Challugulla, M. Young, and E. Cutrell. 2013. Local Pocket Internet and Global Social Media. Bridging the Digital Gap: Facebook and Youth Sub-Stratum in Urban India. International Conference on Social Implications of Computers in Developing Countries.

http://research.microsoft.com/apps/pubs/default.aspx?i $\mathrm{d}=193542$

38. Christian Sandvig. 2012. Connection at Ewiiaapaayp Mountain. In Race After the Internet, L Nakamura and P Chow-White (eds.). Routledge, New York, NY, 168200.

39. Nancy Scola. 2014. Only 5 percent of Cubans can get on the same Internet Americans do. That could soon change. Washington Post. Retrieved April 20, 2015 from http://www.washingtonpost.com/blogs/theswitch/wp/2014/12/17/cubans-might-soon-actually-beable-to-get-on-the-real-internet/

40. Irina Shklovski and Nalini Kotamraju. 2011. Online contribution practices in countries that engage in internet blocking and censorship. Proceedings of the SIGCHI Conference on Human Factors in Computing 
Systems (CHI '11), ACM Press, 1109-1118. http://doi.org/10.1145/1978942.1979108

41. Thomas N. Smyth, John Etherton, and Michael L. Best. 2010. MOSES. Proceedings of the SIGCHI Conference on Human Factors in Computing Systems (CHI '10), ACM Press, 1059. http://dl.acm.org/citation.cfm?id=1753326.1753484

42. Anselm Strauss and Juliet Corbin. 1998. Basics of qualitative research: Procedures and techniques for developing grounded theory. Sage, Thousand Oaks, CA.

43. Juan O. Tamayo. 2014. Cuba allows phone access to some email. Miami Herald. Retrieved May 12, 2015 from http://www.miamiherald.com/news/local/indepth/article 1961145.html

44. The White House. 2014. FACT SHEET: Charting a New Course on Cuba. Retrieved May 12, 2015 from https://www.whitehouse.gov/the-pressoffice/2014/12/17/fact-sheet-charting-new-course-cuba

45. Sabrina Toppa. 2015. Cuba Gets First Free Public WiFi Spot. Time. Retrieved May 14, 2015 from http://time.com/3747118/cuba-first-free-public-wifispot/

46. Sherry Turkle. 2012. Alone Together: Why We Expect More from Technology and Less from Each Other. Basic Books.

47. Rosa Tania Valdes. 2014. Raul Castro's reforms fail to end Cuba's chronic shortages. Reuters. Retrieved July 26, 2015 from http://www.reuters.com/article/2014/05/09/us-cubashortages-idUSBREA480DC20140509

48. Cristina Venegas. 2010. Digital Dilemmas: The State, the Individual, and Digital Media in Cuba. Rutgers University Press, Piscataway, NJ.

49. Claire Voeux and Julien Pain. 2006. Going Online in Cuba: Internet Under Surveillance. Reporters Without Borders. Retrieved May 6, 2015 from http://www.rsf.org/IMG/pdf/rapport_gb_md_1.pdf

50. Judy Wajcman. 2008. Life in the fast lane? Towards a sociology of technology and time. The British Journal of Sociology 59, 1, 59-77. http://www.ncbi.nlm.nih.gov/pubmed/18321331

51. Santiago Wills. 2013. The Internet in Cuba: Facts and Myths About Web Access. ABC News. Retrieved April 30, 2015 from http://abcnews.go.com/ABC_Univision/internet-cubafacts-myths-web-access/story?id=19895951

52. Peter Wolcott, Larry Press, William McHenry, Seymour Goodman, and William Foster. 2001. A Framework for Assessing the Global Diffusion of the Internet. Journal of the Association for Information Systems 2, 6, 1-50. http://aisel.aisnet.org/cgi/viewcontent.cgi?article=1181 \&context=jais

53. Volker Wulf, Konstantin Aal, Ibrahim Abu Kteish, et al. 2013. Fighting Against the Wall: Social Media use by Political Activists in a Palestinian Village. Proceedings of the SIGCHI Conference on Human Factors in Computing Systems (CHI '13), ACM Press, 1979-1988. http://doi.org/10.1145/2470654.2466262

54. Susan P Wyche, Andrea Forte, and Sarita Yardi Schoenebeck. 2013. Hustling online: understanding consolidated facebook use in an informal settlement in Nairobi. Proceedings of the SIGCHI Conference on Human Factors in Computing Systems (CHI'13). http://dl.acm.org/citation.cfm?id=2481391

55. Susan P Wyche, Sarita Yardi Schoenebeck, and Andrea Forte. 2013. Facebook is a luxury: An exploratory study of social media use in rural kenya. Proceedings of the SIGCHI Conference on Computer Supported Collaborative Work and Social Computing (CSCW '13). http://dl.acm.org/citation.cfm?id=2441783

56. Lana Wylie and Lisa Glidden. 2013. The'Cuban Spring' Fallacy: The Current Incarnation of a Persistent Narrative. International Journal of Cuban Studies. http://www.jstor.org/stable/10.13169/intejcubastud .5.2. 0140

57. Alan Yuhas. 2015. Airbnb and Cuba: a match made in capitalist heaven. The Guardian. Retrieved July 25, 2015 from http://www .theguardian.com/technology/2015/apr/02/ai rbnb-cuba-apartments-houses-american-tourists

58. Ethan Zuckerman. 2007. The connection between cute cats and web censorship. Retrieved July 24, 2015 from http://www .ethanzuckerman.com/blog/2007/07/16/theconnection-between-cute-cats-and-web-censorship/

59. 2015. Historic Poll: Top 25 findings from major Cuba survey. Fusion. Retrieved May 1, 2015 from http://fusion.net/story/116226/historic-poll-top-25findings-from-major-cuba-survey/ 